Journal of Clinical Investigation

Vol. 42, No. 9, 1963

\title{
REDUCED VASCULAR RESPONSE TO ANGIOTENSIN II IN SECONDARY HYPERALDOSTERONISM *
}

\author{
By C. I. JOHNSTON ANd ANTHONY D. JOSE \\ (From the Hallstrom Institute of Cardiology, Royal Prince Alfred Hospital, Sydney, \\ Australia)
}

(Submitted for publication February 8, 1963; accepted May 17, 1963)

Recent investigations have suggested that the kidney may be concerned in the control of aldosterone production by the adrenals $(1,2)$. The renin content of kidney tissue correlates well with the thickness of the zona glomerulosa of the adrenal cortex and with the measured aldosterone production rate $(3,4)$. Angiotensin has been shown to stimulate aldosterone production both in man $(5,6)$ and in intact animals $(4,7)$, and it is a powerful stimulus to the biosynthesis of aldosterone in vitro $(4,8)$. Although its role under normal physiological conditions is not clear (7), the renin-angiotensin system has been implicated in the maintenance of certain states of experimentally produced hyperaldosteronism (9), and angiotensin may be an aldosterone-stimulating hormone $(\mathrm{ASH})$. Elevated angiotensin levels have been found in the thoracic lymph of dogs with hyperaldosteronism induced by inferior vena caval constriction (10), but there are no reported studies of angiotensin levels in humans with hyperaldosteronism.

Since angiotensin is a powerful pressor agent (11), it is of interest that most patients with secondary hyperaldosteronism are not hypertensive. Infusion of subpressor amounts of angiotensin in the dog will significantly increase aldosterone production (12), but not to the extent commonly found in secondary hyperaldosteronism. Blair-West and associates (7) demonstrated a threshold level of angiotensin for the sheep's adrenal and estimated this to be 0.20 to $0.25 \mu \mathrm{g}$ per L of plasma, a level that produces significant pressor effects in the sheep and in humans.

Experimental hyperaldosteronism in $\operatorname{dogs}$ is

* Presented in part at the 2nd Annual Meeting of the Australian Society for Medical Research, Canberra, October 13-14, 1962. Abstract published in Med. Res., Journal of the Australian Society for Medical Research $1962,2,41$. This work was supported by grant G28 from the National Heart Foundation of Australia. accompanied by a reduced pressor response to infused angiotensin (1), and it was observed that patients with cirrhosis and ascites had a reduced pressor response to angiotensin $(13,14)$. We therefore thought it valuable to compare the vascular sensitivity to angiotensin in patients with secondary hyperaldosteronism and in control subjects.

\section{METHODS}

Studies have been made on nine control subjects (group 1), on seven patients with cirrhosis of the liver and four patients with nephrotic syndrome, all with evidence of hyperaldosteronism (group 2), on three patients with resistant cardiac failure and evidence of hyperaldosteronism (group 3), and on two patients with cirrhosis of the liver without evidence of hyperaldosteronism (group 4) (Table I).

Group 1 comprised three normal students and six patients convalescing from a variety of diseases. None showed any cardiovascular, hepatic, or renal disorder or fluid retention. The urinary excretion ratio of sodium to potassium was consistently greater than 2 .

The individual diagnoses of patients in groups 1,2 , and 3 are given in Table $I$, with the resting mean arterial blood pressure and cardiac output. Their serum levels of sodium and potassium and their current diuretic therapy are also shown. Hyperaldosteronism was presumed to be present by the following criteria : chronic edema and ascites were present, the urinary excretion ratio of sodium to potassium was consistently less than 0.5 , and spironolactone produced a significant rise in the urinary sodium to potassium excretion ratio. Aldosterone production or urinary levels were not measured.

In the two patients of group 4, there was no evidence of fluid retention, and the urinary sodium to potassium excretion ratio was consistently greater than 2 .

The studies were made with the patient lying supine, premedicated with sodium pentobarbital, $1 \frac{1}{2} \mathrm{~g}$. A needle was inserted into the brachial artery, and a fine polythene catheter was introduced percutaneously into the superior vena cava. Arterial blood pressure was measured by a strain gauge transducer and recorded continuously with the electrocardiogram. Mean arterial pressure was obtained by electronic integration. Cardiac output was measured by the dye dilution method using indocyanine green and a Gilford cuvette densitometer. 
TABLE I

Basal blood pressure (BP), systemic vascular resistance (SVR), cardiac output, serum electrolytes, diagnosis, and diuretic therapy of patients studied

\begin{tabular}{|c|c|c|c|c|c|c|c|c|c|}
\hline \multicolumn{2}{|c|}{ Patient } & \multirow[b]{2}{*}{ BSA } & \multirow{2}{*}{$\begin{array}{c}\text { Basal } \\
\text { mean } \\
\text { BP }\end{array}$} & \multirow{2}{*}{$\begin{array}{l}\text { Basal } \\
\text { SVR }\end{array}$} & \multirow{2}{*}{$\begin{array}{l}\text { Cardiac } \\
\text { output }\end{array}$} & \multicolumn{2}{|c|}{ Serum } & \multirow[b]{2}{*}{ Diagnosis } & \multirow{2}{*}{$\begin{array}{l}\text { Diuretic } \\
\text { therapy }\end{array}$} \\
\hline Sex & Age & & & & & $\overline{\mathrm{Na}}$ & $\overline{\mathbf{K}}$ & & \\
\hline & years & $m^{2}$ & $m m \mathrm{Hg}$ & $\underset{\substack{\text { dynes-sec- } \\
\mathrm{cm}^{-5}}}{\text { - }}$ & $L / \min$ & \multicolumn{2}{|c|}{$m E q / L$} & & \\
\hline \multicolumn{10}{|c|}{ Group 1 : Control subjects } \\
\hline $\mathbf{M}$ & 61 & 2.25 & 100 & 1,114 & 7.18 & & & Normal & \\
\hline $\mathbf{F}$ & 42 & 1.71 & 99 & 839 & 9.44 & & & Normal & \\
\hline $\mathbf{F}$ & 26 & 1.48 & 80 & 862 & 7.43 & & & Normal & \\
\hline $\mathbf{M}$ & 65 & 1.72 & 68 & 1,767 & 4.35 & & & Syringomyelia & \\
\hline $\mathbf{M}$ & 42 & 1.66 & 101 & 1,594 & 5.07 & & & Myelofibrosis & \\
\hline $\mathbf{M}$ & 47 & 1.65 & 104 & 2,060 & 4.05 & & & Ankylosing spondylitis & \\
\hline $\mathbf{M}$ & 58 & 1.88 & 76 & 1,767 & 3.44 & & & Pneumonia & \\
\hline $\mathbf{M}$ & 25 & 1.87 & 98 & 906 & 8.66 & & & Viral infection & \\
\hline $\mathbf{F}$ & 21 & 1.40 & 80 & 656 & 9.75 & & & Pulmonary tuberculosis & \\
\hline \multicolumn{10}{|c|}{ Group 2: Patients with cirrhosis or nephrosis with hyperaldosteronism } \\
\hline $\mathbf{M}$ & 46 & 2.33 & 69 & 723 & 9.04 & 131 & $\mathbf{3 . 0}$ & Cirrhosis & $C \ddagger$ \\
\hline $\mathbf{F}$ & 55 & 1.53 & 61 & 790 & 6.18 & 124 & 4.0 & Cirrhosis & C \\
\hline $\mathbf{F}$ & 43 & 1.37 & 85 & 1,015 & 6.37 & 135 & 3.6 & Cirrhosis & $C \ddagger$ \\
\hline $\mathbf{M}$ & 36 & 1.69 & 84 & 976 & 6.88 & 130 & 3.8 & Cirrhosis & $C \ddagger$ \\
\hline $\mathbf{M}$ & 51 & 1.71 & 83 & 977 & 6.80 & 132 & 3.1 & Cirrhosis & $C \ddagger$ \\
\hline $\mathbf{M}$ & 50 & 1.58 & 92 & 1,002 & 7.51 & 127 & 3.3 & Cirrhosis & \\
\hline $\mathbf{M}$ & 51 & 1.91 & 85 & 757 & 8.98 & 128 & 4.3 & Cirrhosis & \\
\hline $\mathbf{M}$ & 27 & 1.71 & 75 & 761 & 6.18 & 134 & 4.4 & Nephrotic syndrome & $C \ddagger$ \\
\hline $\mathbf{M}$ & 35 & 1.96 & 126 & 1,548 & 6.51 & 129 & 4.1 & Nephrotic syndrome & Ct \\
\hline $\mathbf{M}$ & 16 & 1.69 & 98 & 875 & 8.96 & 135 & 4.7 & Nephrotic syndrome & $C \ddagger$ \\
\hline $\mathbf{M}$ & 31 & 1.77 & 100 & 1,400 & 5.71 & 133 & 3.8 & Nephrotic syndrome & $C \ddagger$ \\
\hline \multicolumn{10}{|c|}{ Group 3: Patients with congestive cardiac failure with hyperaldosteronism } \\
\hline $\mathbf{F}$ & 34 & 1.43 & 91 & 3,552 & 2.05 & 138 & 4.6 & $\underset{\text { Resistant CCFt }}{\text { CRHD* }}$ & $C \ddagger$ \\
\hline $\mathbf{F}$ & 36 & 1.50 & 90 & 3,674 & 1.96 & 138 & 3.9 & $\begin{array}{l}\text { CRHD* } \\
\text { Resistant CCF }\end{array}$ & $\mathbf{C} \ddagger$ \\
\hline $\mathbf{M}$ & 54 & 1.47 & 65 & 1,736 & 3.00 & 137 & 3.2 & $\begin{array}{c}\text { Constrictive } \\
\text { pericarditis }\end{array}$ & S\& \\
\hline \multicolumn{10}{|c|}{ Group 4: Patients with cirrhosis without hyperaldosteronism } \\
\hline $\mathbf{F}$ & 45 & 1.44 & 127 & 1,336 & 7.62 & 142 & 4.9 & Cirrhosis & \\
\hline $\mathbf{F}$ & 58 & 1.49 & 69 & 1,878 & 2.94 & 136 & 4.2 & Cirrhosis & \\
\hline
\end{tabular}

* Chronic rheumatic heart disease. Congestive cardiac failure. Spironolactone.

After a control period during which resting blood pressure and cardiac output were measured, a rapid injection of $0.25 \mu \mathrm{g}$ of angiotensin II $^{1}$ was made into the vena cava. The arterial pressure usually rose within 2 minutes, remained at a plateau for 5 to 6 minutes, and then fell to the resting level. A measurement of cardiac output was made during the plateau of the blood pressure rise between 3 and 4 minutes after the injection of angiotensin.

The measurements were repeated with increasing doses of angiotensin at intervals of 15 to 20 minutes, so that three or four dose-response points were obtained for each patient, with doses varying from 0.25 to $5.0 \mu \mathrm{g}$ of angiotensin II.

In six control subjects and ten group 2 patients, the response was measured to a single dose of $10 \mu \mathrm{g}$ of $l$-norepinephrine ${ }^{2}$ given in the same manner.

1 Val-5-angiotensin, Hypertensin, Ciba Ltd., Basel, Switzerland.

$2 l$ - $\alpha$-(Aminomethyl) -3,4-dihydroxybenzyl alcohol.
In two control subjects (M 25 and F 21, Table I), the response to angiotensin was remeasured 30 minutes after the iv administration of $2 \mathrm{mg}$ of $d$-aldosterone.

The maximal mean arterial pressure and cardiac output were measured for each injection. The systemic vascular resistance (SVR) was calculated by dividing mean arterial pressure $(\mathrm{mm} \mathrm{Hg}$ ) by the cardiac output (liters per minute) and converting to absolute units of dyne$\mathrm{sec}-\mathrm{cm}^{-5}$. No measurement or correction was made for right atrial pressure.

\section{RESULTS}

Patients with cirrhosis or nephrosis with hyperaldosteronism (group 2)

Changes in arterial pressure. The resting mean arterial pressure in the control subjects, group 1 (average $90 \pm \mathrm{SD} 13 \mathrm{~mm} \mathrm{Hg}$ ), ${ }^{3}$ was not sig-

\footnotetext{
${ }^{3}$ All estimates of variance are $\pm 1 \mathrm{SD}$
} 


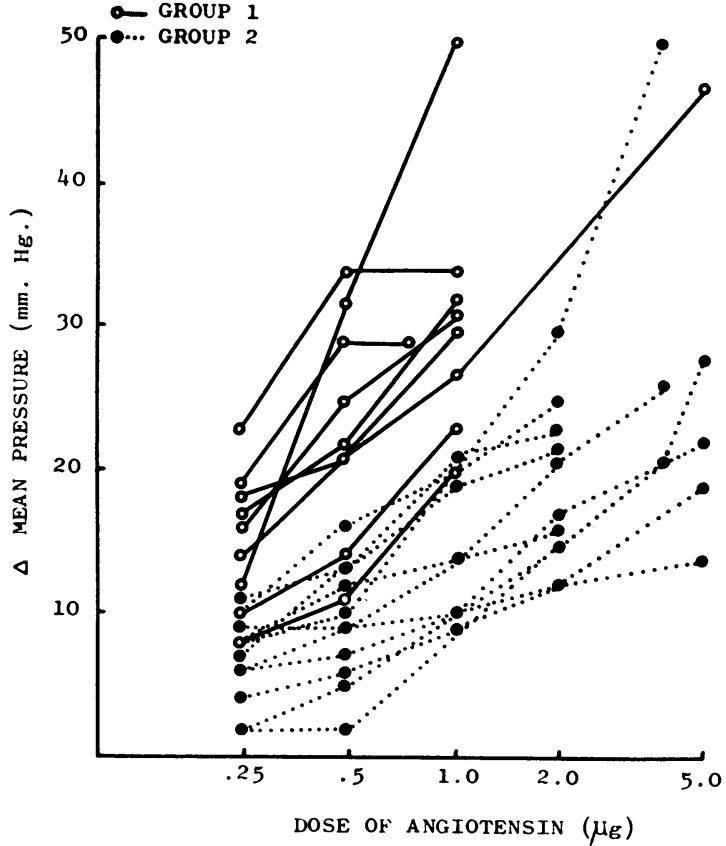

Fig. 1. INDIVIdUAL DOSE-RESPONSE LINES OF MAXIMAL RISE IN MEAN ARTERIAL PRESSURE $(\triangle \mathrm{BP})$ FOR PATIENTS IN GROUPS 1 AND 2 .

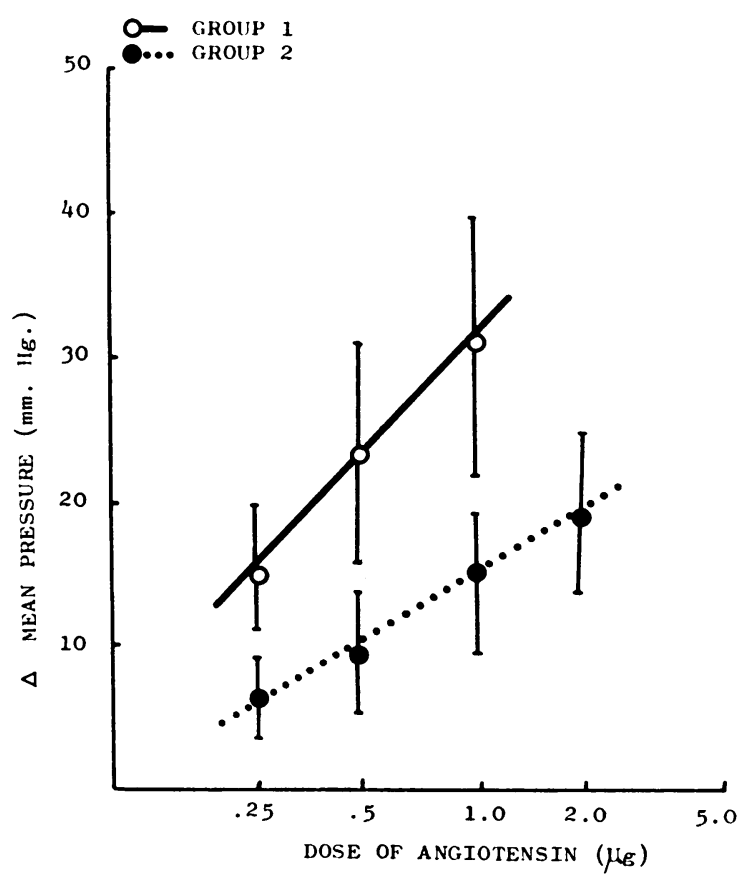

Fig. 2. LiNEAR-REGRESSION LINES OF RISE IN MEAN ARTERIAL PRESSURE ( $\triangle \mathrm{BP}$ ) PER DOSE OF ANGIOTENSIN FOR GROUP 1 AND GROUP 2 AND MEAN RESPONSE OF $\triangle B P \pm 1$ SD FOR VARYING DOSES OF ANGIOTENSIN FOR BOTH GROUPS, The calculated linear regression equations are: for group $1, \mathrm{y}=25.3 \log \mathrm{x}+30.7$ and for group $2, \mathrm{y}=14.8$ $\log \mathrm{x}+14.7$.

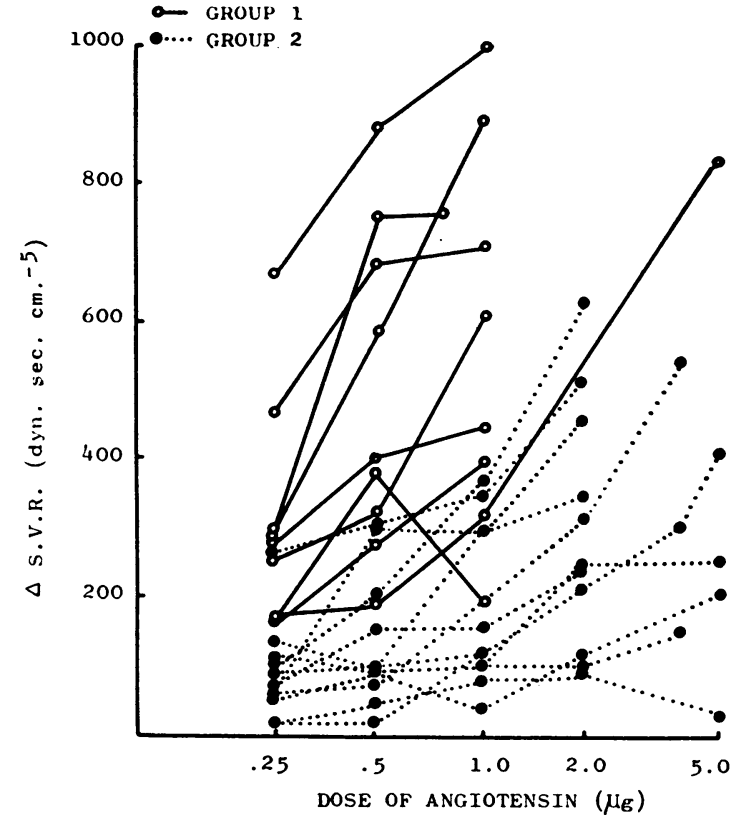

FIG. 3. INDIVIDUAL DOSE-RESPONSE LINES OF RISE IN SYSTEMIC VASCULAR RESISTANCE ( $\triangle$ SVR) FOR PATIENTS IN GROUPS 1 AND 2.

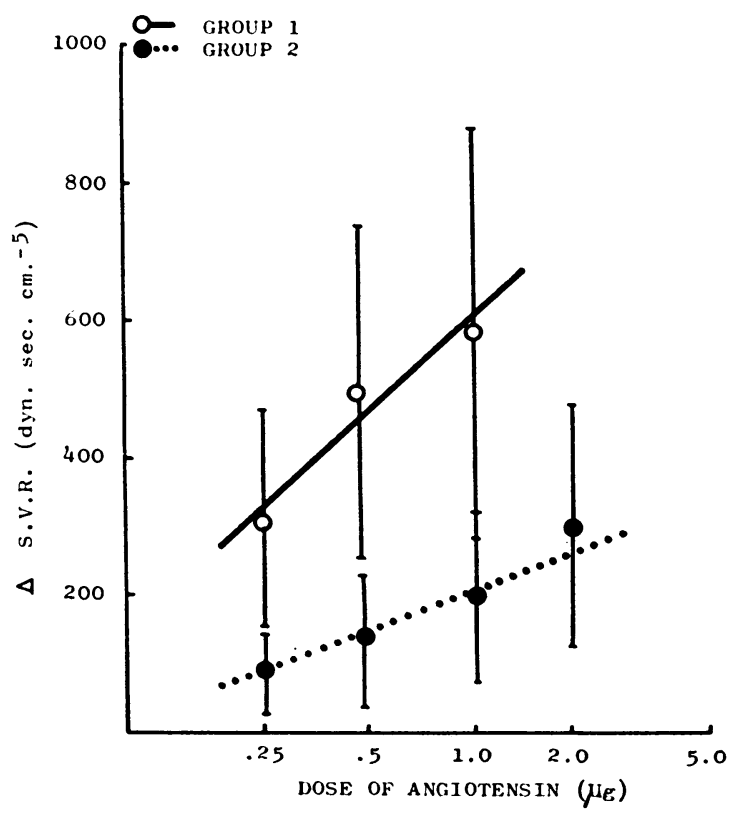

Fig. 4. LINEAR-REGRESSION LINES OF RISE IN SYSTEMIC VASCULAR RESISTANCE ( $\triangle$ SVR) PER DOSE OF ANGIOTENSIN FOR GROUP 1 AND GROUP 2 AND MEAN RESPONSES OF $\triangle S V R \pm 1$ SD FOR VARYING DOSES OF ANGIOTENSIN FOR вOTH GROUPS. The calculated linear regression equations are: for group $1, y=442 \log x+600$ and for group. 2, $y=185 \log x+201$. 


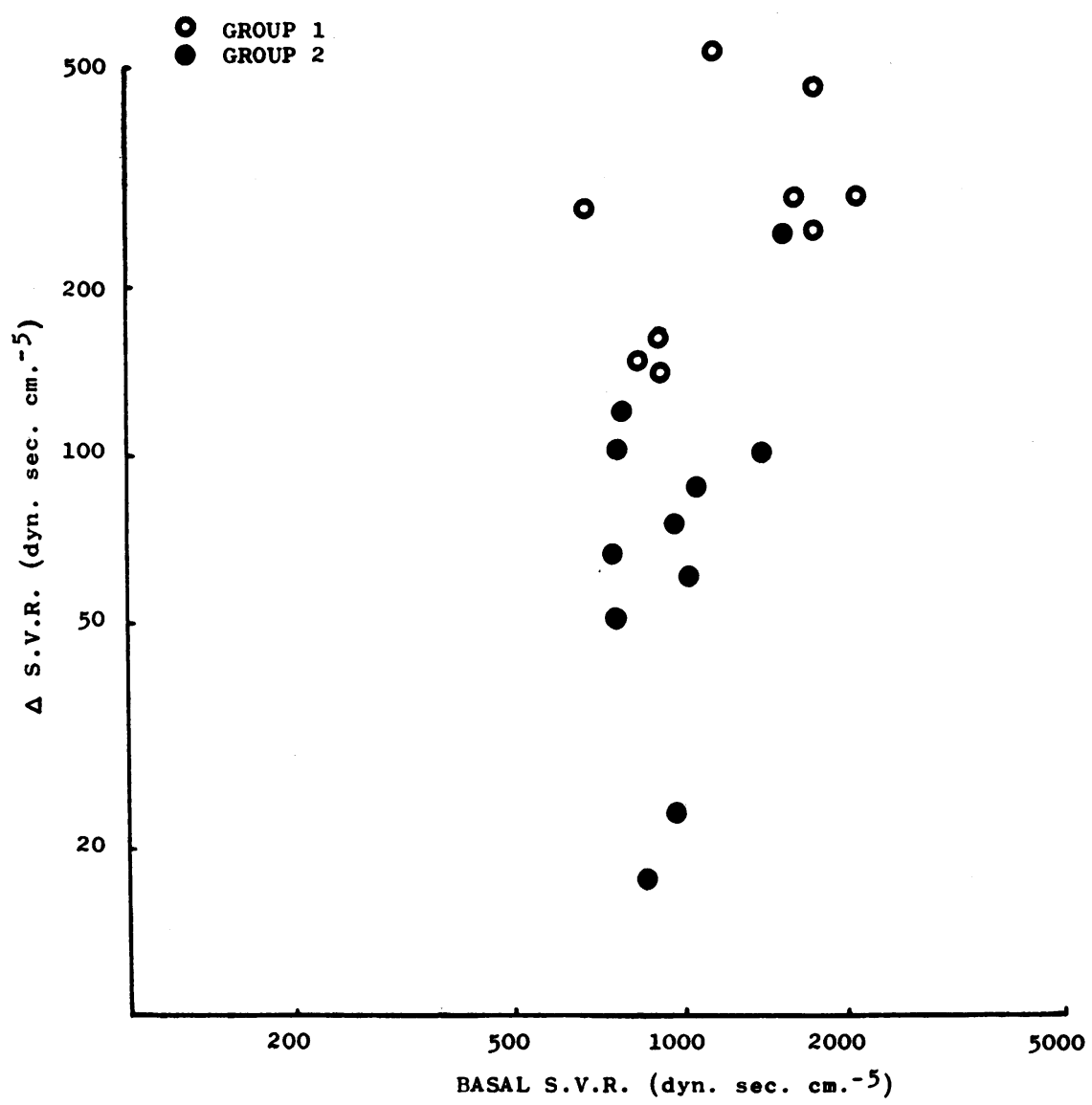

Fig. 5. RELATIONSHIP BETWEEN RISE IN SYSTEMIC VASCULAR RESISTANCE ( $\Delta$ SVR) AND RESTING SYSTEMIC VASCULAR RESISTANCE ON LOG-LOG SCALE FOR PATIENTS IN GROUPS 1 AND 2. $\triangle$ SVR in this graph is the value found after the administration of $0.25 \mu \mathrm{g}$ of angiotensin II to each patient.

nificantly different from the group 2 patients (average $87 \pm \mathrm{SD} 17 \mathrm{~mm} \mathrm{Hg}$ ), $\mathrm{p}>0.7$, by $t$ test. The pressor response of each patient, measured as the maximal rise in mean arterial pressure $(\triangle \mathrm{BP})$ for each dose of angiotensin, is shown as a dose-response line, and in Figure 1 the responses of the patients in groups 1 and 2 are compared. A clear reduction in pressor response at all dose levels of angiotensin is evident in patients with hyperaldosteronism compared to the control subjects.

The linear regression lines calculated from the pooled data for each group are: for group 1, $\mathrm{y}=25.3 \log \mathrm{x}+30.7(\mathrm{r}=0.76)$ and for group $2, \mathrm{y}=14.8 \log \mathrm{x}+14.7(\mathrm{r}=0.73)$, where $\mathrm{y}$ is the increment in mean arterial pressure $(\triangle \mathrm{BP})$ and $x$ is the dose in micrograms of angiotensin given. The difference between the two regression lines tested against the residual error, using the " $F$ " test, gave a significance level of less than $0.1 \%$. These lines are shown in Figure 2, together with the mean response $\pm 1 \mathrm{SD}$ at each dose level of angiotensin for the two groups.

Changes in SVR. The resting levels of SVR were not significantly different in the two groups of patients (average 1,285 \pm 513 dyne-sec- $\mathrm{cm}^{-5}$ in group 1, average $984 \pm 266$ dyne-sec- $\mathrm{cm}^{-5}$ in group 2, $\mathrm{p}>0.2)$. The rise in SVR $(\Delta \mathrm{SVR})$ for each dose of angiotensin, plotted as individual dose-response lines (Figure 3 ), again shows a clearly reduced response in patients with hyperaldosteronism. The linear regression lines calculated from the pooled data for each group are: for group 1, $y=442 \log x+600(r=0.52)$ and 
for group 2, $\mathrm{y}=185 \log \mathrm{x}+201 \quad \mathrm{r}=0.53)$, where $y$ is the rise in SVR $(\triangle \mathrm{SVR})$ and $\mathrm{x}$ is the dose of angiotensin in micrograms. These lines are shown in Figure 4, together with the mean response $\pm 1 \mathrm{SD}$ at each dose level of angiotensin for the two groups. The difference between the two groups is significant at the $0.1 \%$ level.

Although the averages of the resting SVR in each group are similar, there is within each group a tendency for those with the higher resting SVR to have a greater $\Delta S V R$ for a given dose of angiotensin. This is seen in Figure 5, where the $\Delta S V R$ for the $0.25-\mu \mathrm{g}$ dose of angiotensin is plotted against the resting SVR on a log-log scale. This phenomenon would be expected in a physical system in view of the dependence of the SVR on the fourth power of a vessel radius. A firstorder correction for this phenomenon has been made by using percentile elevation of SVR $(\% \Delta \mathrm{SVR})$ as the response to angiotensin and plotting dose-response lines as before (Figure 6).

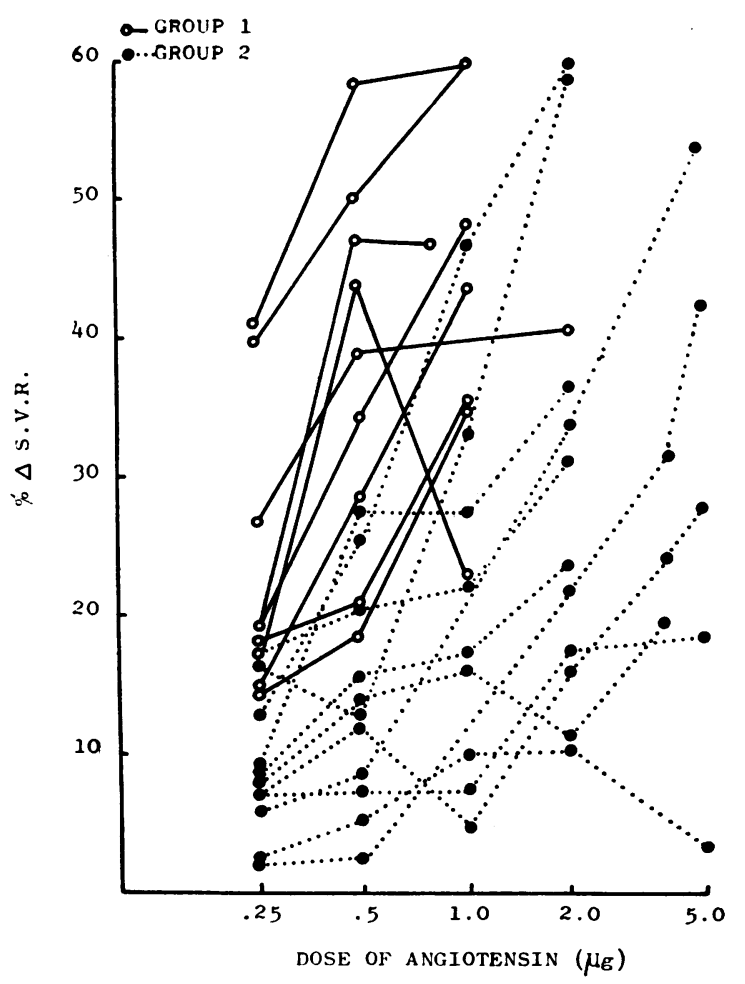

FIG. 6. INDIVIDUAL DOSE-RESPONSE LINES OF PERCENTILE RISE OF SYSTEMIC VASCULAR RESISTANCE ( $\% \Delta \mathrm{SVR}$ ) FOR PATIENTS IN GROUPS 1 AND 2.

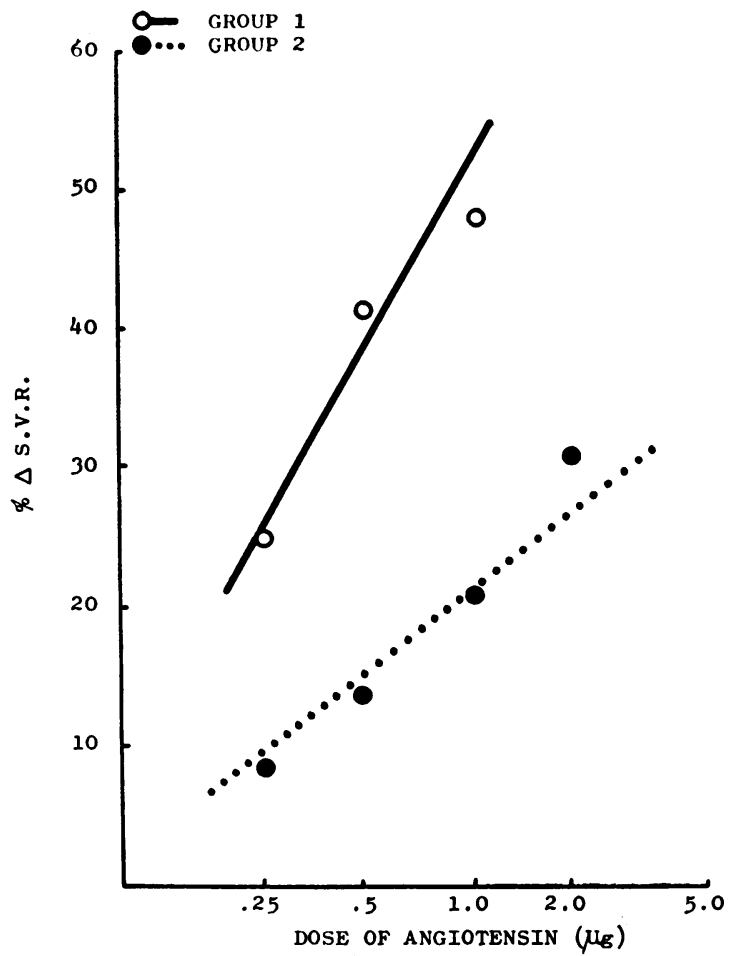

Fig. 7. LiNEAR-REgRESSION LINES OF PERCENTILE RISE IN SYSTEMIC VASCULAR RESISTANCE ( $\% \Delta$ SVR) PER DOSE OF ANGIOTENSIN FOR GROUP 1 AND GROUP 2 AND MEAN RESPONSE OF $\% \triangle$ SVR FOR VARYING DOSES OF ANGIOTENSIN FOR BOTH GROUPS. The calculated linear regression equations are: for group $1, \mathrm{y}=44.3 \log \mathrm{x}+52.1$ and for group $2, \mathrm{y}=18.8 \log \mathrm{x}+20.8$.

The regression lines from the pooled data for each group are: for group $1, y=44.3 \log x+$ $52.1(\mathrm{r}=0.61)$ and for group $2, \mathrm{y}=18.8 \log \mathrm{x}$ $+20.8(\mathrm{r}=0.50)$, where $\mathrm{y}$ is the percentile rise in SVR $(\% \Delta \mathrm{SVR})$ and $\mathrm{x}$ the dose of angiotensin in micrograms. These lines are shown in Figure 7 together with the mean response at each dose level of angiotensin for the two groups. The difference in response between the two groups is still significant at the $0.1 \%$ level.

Response to l-norepinephrine. No reduction in sensitivity of the group 2 patients was found to an injection of $10 \mu \mathrm{g}$ of $l$-norepinephrine. The mean arterial pressure rose by an average of 30.4 $\pm 11 \mathrm{~mm} \mathrm{Hg}$ in six control subjects, and by an average of $29.4 \pm 14 \mathrm{~mm} \mathrm{Hg}$ in ten group 2 patients.

The measurement of SVR at the same time showed an average rise of $580 \pm 184$ dyne-sec- 
$\mathrm{cm}^{-5}$ in the control subjects and a rise of $400 \pm$ 320 dyne-sec- $\mathrm{cm}^{-5}$ in group 2 patients. The difference was not statistically significant, $\mathrm{p}>0.2$. The $\% \Delta \mathrm{SVR}$ in the two groups were very similar, averaging $48.2 \%$ in the controls and $41.2 \%$ in the group 2 patients.

Patients with congestive cardiac failure with hyperaldosteronism (group 3)

These patients are considered separately because aldosterone production is rarely elevated to as high a level in resistant heart failure as in cirrhosis or nephrosis, and the circulatory disorder in heart failure might have influenced their response to angiotensin.

Their responses, however, were very similar (Figure 8) to group 2 patients. The dose-response lines in all three fell below the regression line for group 2 patients. Inclusion of these patients with group 2 enhanced the differences from the control subjects in group 1 .

\section{Patients with cirrhosis without hyperaldosteronism (group 4)}

Two patients with cirrhosis of the liver proved by liver biopsy, but without fluid retention, and whose urinary excretion ratio of sodium to potassium did not suggest increased aldosterone production were also studied. Their responses to angiotensin (Figure 8) were normal, both lines falling above the regression line for the control subjects in group 1.

Influence of d-aldosterone. The response to angiotensin at three dose levels in two control subjects (M25 and F21, Table I) was not significantly altered 30 minutes after the iv admin-

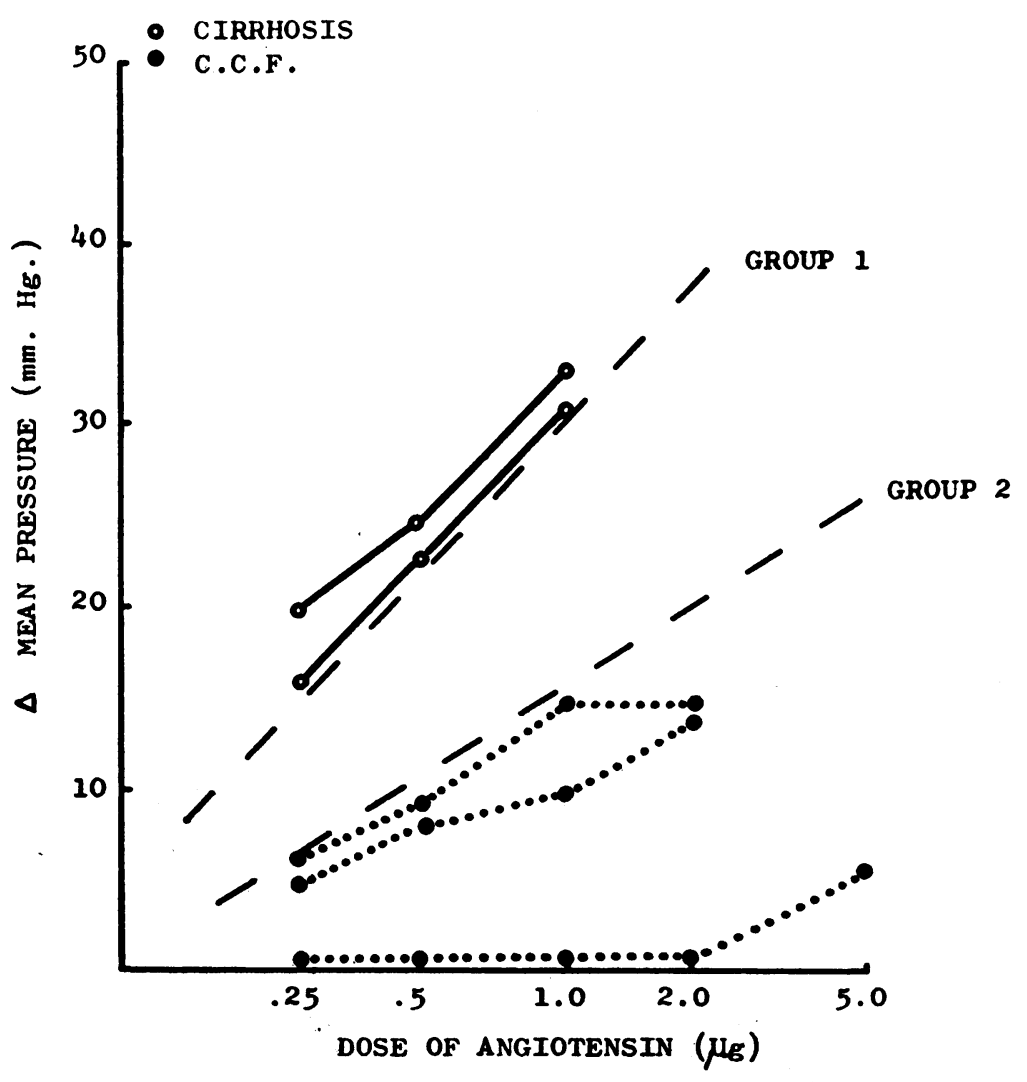

Fig. 8. Dose-RESPonse lines of MAXIMAL RISE IN MEAN ARTERIAL PRESSURE ( $\triangle B P$ ) FOR TWO PATIENTS WITH CIRRHOSIS WITHOUT SECONDARY HYPERALDOSTERONISM (GROUP 4) AND THREE PATIENTS WITH CONGESTIVE CARDIAC FAILURE AND SECONDARY HYPERALDOSTERONISM (GROUP 3 ). The linear-regression lines for group 1 and group 2 are shown for comparison. 
istration of $2 \mathrm{mg}$ of $d$-aldosterone with regard to both $\triangle \mathrm{BP}$ and $\triangle \mathrm{SVR}$.

\section{DISCUSSION}

The results clearly establish that angiotensin produced very different increments in arterial pressure and vascular resistance in patients with hyperaldosteronism and in control subjects. The difference in response of the SVR demonstrates that the smaller $\triangle \mathrm{BP}$ to angiotensin II in hyperaldosteronism, as reported previously $(1,13,14)$, is due, in fact, to reduced vascular reactivity rather than to other hemodynamic changes.

No precise relationship can be defined, however, between the increment in measured SVR and a change in vascular muscle tone because of the anatomic complexities of the vascular bed and of the interaction between the muscle and connective tissue elements of vessel walls (15). As stated earlier, a tendency might be expected for the same change in vascular tone to produce a greater $\triangle \mathrm{SVR}$ in patients whose initial SVR was high. It is not possible, however, that this tendency alone could explain the difference found in our study; the averages of the resting SVR in each group were similar, yet the averages of $\Delta$ SVR for each dose of angiotensin were significantly different; the difference was not affected by making a first-order correction for the initial SVR (Figures 6 and 7). The data shown in Figure 5 further support this conclusion. There is a very poor relationship between the $\triangle \mathrm{SVR}$ and the resting SVR. It has also been demonstrated previously that the initial level of blood pressure or narrowing of the arterioles by vascular spasm does not influence the response to pressor amines (16).

Patients with edema and ascites have a greatly expanded extracellular space. Hence, in these patients, many drugs have a larger volume of distribution and consequently reach a lower blood concentration for a given dose. Angiotensin II, however, is a large polypeptide and in vivo may be loosely bound to protein (11); its immediate volume of distribution is therefore probably only that of the blood volume. The blood volumes of patients with cirrhosis (17) and congestive cardiac failure (18) may be increased up to $20 \%$. This extra degree of dilu- tion of injected angiotensin would appear to be insufficient to account for the large difference in response which required that patients in groups 2 and 3 be given 4 to 10 times the dose of angiotensin to obtain a pressor response equal to the controls. Patients with the nephrotic syndrome have been shown to have a reduced blood volume (19.20), so greater dilution of the administered dose obviously cannot be a factor in their reduced response.

The data, therefore, demonstrate a reduced vascular response to angiotensin in the patients of groups 2 and 3. It is of interest to consider the various possible mechanisms for this lowered sensitivity to angiotensin.

Vasodepressor substances have been demonstrated in the blood of cirrhotic patients (21), but there is no reason to believe they occur in nephrosis or congestive cardiac failure. For this reason, we studied two patients with cirrhosis proved by liver biopsy (group 4, Table I) who did not appear to have an increased aldosterone production. These two patients had normal responses to angiotensin (Figure 8).

The depressed response to angiotensin occurred in patients with three unrelated disease states, having in common only the presence of edema and evidence of hyperaldosteronism. It is logical, therefore, to assume that the same mechanism is responsible in cirrhosis, nephrosis, and congestive cardiac failure and to relate their abnormal sensitivity to angiotensin with these common features.

Aldosterone itself seems unlikely to cause such a change, and we were unable to produce an abnormal response in two control subjects by the acute administration of aldosterone.

Electrolyte disturbances may occur in patients with secondary hyperaldosteronism, especially since they have usually been treated over long periods with diuretic drugs. The contractility of aortic strips in vitro can be modified by changing their electrolyte environment; by increasing the sodium ion concentration and lowering the potassium ion concentration in the perfusing fluid, their contractility to pressor amines is depressed (22). The majority of the patients in groups 2 and 3 had a low serum potassium level (Table I), but they also had low serum sodium concentrations, and this, in vitro, has been reported 
to increase the contractility of arterial smooth muscle to pressor drugs (23) and particularly to angiotensin (24). Friedman and Allardyce (25) also showed the importance of ionic distribution, particularly of sodium, in the maintenance of tension in artery segments. Chlorothiazide ${ }^{4}$ has been shown to modify the pressor response to infused $l$-norepinephrine (26-28), and dogs given prior treatment with 3,4-dihydrochlorothiazide $^{5}$ have a diminished pressor response to angiotensin (29). These were all acute experiments. The initial hypotensive action of chlorothiazide may be due to a fall in blood volume and is partially reversed by plasma expansion (27). The blood volume returns to normal, however, after several weeks (30), while a hypotensive action persists. Some workers have found that chlorothiazide therapy does not affect total body or tissue electrolyte concentrations (30-32), and it has been suggested that the drug has a direct action on peripheral vessels (33, $34)$. We know of no studies that have shown a reduced response to pressor agents after longterm diuretics. Since all 14 patients with hyperaldosteronism probably had disturbances in electrolyte distribution and had low serum concentrations of potassium and sodium (Table I), and since 12 of the 14 were receiving diuretic therapy at the time of study, these factors cannot be excluded as determinants of their reduced sensitivity to angiotensin, although two of the 14 had not received diuretics.

All ten of the patients with hyperaldosteronism who were studied with $l$-norepinephrine showed normal pressor sensitivity to this drug. Eight of these patients were receiving chlorothiazide, which in acute experiments depresses the response to $l$-norepinephrine. It is unlikely, therefore, that the reduced sensitivity to angiotensin was caused by a general depression of vascular contractile properties. This apparent dissociation suggests a more specific mechanism.

The term tachyphylaxis has been used to describe the insensitivity or refractiveness to the response of a drug that develops after prolonged or repeated exposure to that drug. . Tachyphy-

4 6-Chloro-7-sulfamoyl-2H-1,2,4-benzothiadizine 1,1-dioxide.

5 6-Chloro-3,4-dihydro-7-sulfamoyl-2H-1,2,4-benzothiadizine 1,1-dioxide. laxis to angiotensin was originally thought not to occur (11), but it can be demonstrated in vitro in isolated smooth muscle (35). Bock and Gross showed (36) that it could be induced in dogs provided sufficient amounts of angiotensin were given. They also demonstrated cross-resistance to renin while sensitivity to $l$-norepinephrine was retained. Langford, McCao, Suyla, and Alencon (37) have shown in dogs that when tachyphylaxis to the pressor effects of angiotensin was produced, the stimulation to increased aldosterone production remained. Tachyphylaxis has not, however, been demonstrated in man even after prolonged infusions (38).

The present study has demonstrated a relatively specific vascular insensitivity to angiotensin in patients with secondary hyperaldosteronism. If, as has been suggested, such patients have increased levels of angiotensin, then the results may be described as tachyphylaxis to angiotensin and this may explain the absence of systemic hypertension in such patients. The mechanism for such tachyphylaxis, however, is not known and may be due to ionic shifts or other changes.

\section{SUM MARY}

The vascular sensitivity to injected angiotensin II has been compared in 14 patients with evidence of secondary hyperaldosteronism and 9 control subjects. The patients with secondary hyperaldosteronism had a diminished vasoconstrictor response to angiotensin shown by smaller rises in arterial blood pressure and in systemic vascular resistance. A possible explanation for this is the development of tachyphylaxis to angiotensin in these patients. The data are consistent with the hypothesis that angiotensin may be the stimulus to aldosterone production in states of secondary hyperaldosteronism without causing systemic hypertension.

\section{ACKNOWLEDGMENT}

We are indebted to Ciba Ltd. (Basel) for supplying the angiotensin II and $d$-aldosterone used in this study. We also record our appreciation to Mr. V. Bofinger, Department of Mathematical Statistics, University of Sydney, for help with the statistical analysis. 


\section{REFERENCES}

1. Davis, J. O., P. M. Hartroft, E. O. Titus, C. C. J. Carpenter, C. R. Ayers, and H. E. Spiegel. The role of the renin-angiotensin system in the control of aldosterone secretion. J. clin. Invest. 1962, 41, 378.

2. Mulrow, P. J., W. F. Ganong, G. Cera, and A. Kuljian. The nature of aldosterone-stimulating factor in dog kidneys. J. clin. Invest. 1962, 41, 505.

3. Hartroft, W. S., and P. M. Hartroft. New approaches in the study of cardiovascular disease: aldosterone, renin, hypertension and juxtaglomerular cells. Fed. Proc. 1961, 20, 845.

4. Carpenter, C. C. J., J. O. Davis, and C. R. Ayers. Relation of renin, angiotensin II, and experimental renal hypertension to aldosterone secretion. J. clin. Invest. 1961, 40, 2026.

5. Laragh, J. H., M. Angers, W. G. Kelly, and S. Lieberman. Hypotensive agents and pressor substances. The effect of epinephrine, norepinephrine, angiotensin II, and others on the secretory rate of aldosterone in man. J. Amer. Med. Ass. 1960, 174, 234.

6. Genest, J., P. Biron, E. Koiw, W. Nowaczynski, R. Boucher, and M. Chrétien. Studies on the pathogenesis of human hypertension: the adrenal cortex and renal pressor mechanism. Ann. intern. Med. 1961, 55, 12.

7. Blair-West, J. R., J. P. Coghlan, D. A. Denton, J. R. Goding, J. A. Munro, R. E. Peterson, and M. Wintour. Humoral stimulation of adrenal cortical secretion. J. clin. Invest. 1962, 41, 1606.

8. Kaplan, N. M., and F. C. Bartter. The effect of ACTH, renin, angiotensin II, and various precursors on b:osynthesis of aldosterone by adrenal slices. J. clin. Invest. 1962, 41, 715.

9. Davis, J. O., C. C. J. Carpenter, and C. R. Ayers. Relation of renin and angiotensin II to the control of aldosterone secretion. Circulat. Res. 1962, 11, 171.

10. Higgins, J. T., J. O. Davis, and J. Urquhart. Increased angiotensin-like activity in thoracic duct lymph of dogs with experimental secondary hyperaldosteronism. Physiologist 1962, 5, 157.

11. Page, I. H., and F. M. Bumpus. Angiotensin. Physiol. Rev. 1961, 41, 331.

12. Urquhart, J., J. O. Davis, and J. T. Higgins. Effects of prolonged infusion of angiotensin II in unrestrained dogs. Physiologist 1962, 5, 224.

13. Laragh, J. H. Interrelationships between angiotensin, norepinephrine, epinephrine, aldosterone secretion, and electrolyte metabolism in man. Circulation 1962, 25, 203.

14. Laragh, J. H. Hormones and the pathogenesis of congestive heart failure: vasopressin, aldosterone and angiotensin II. Further evidence for renaladrenal interaction from studies in hypertension and in cirrhosis. Circulation 1962, 25, 1015.
15. Burton, A. C. Physical principles of circulating phenomena: the physical equilibria of the heart and blood vessels in Handbook of Physiology, Section 2, Circulation. Washington, D. C., American Physiological Society, 1962, pp. 85-106.

16. Conway, J. Vascular reactivity in experimental hypertension measured after hexamethonium. Circulation 1958, 17, 807.

17. Eisenberg, S. Blood volume in patients with Laennec's cirrhosis of the liver as determined by radioactive chromium-tagged red cells. Amer. J. Med. 1956, 20, 189.

18. Schreiber, S. S., and M. A. Rothschild. Blood volume and heart disease. Progr. cardiovasc. Dis. 1962, 4, 565.

19. Waterfield, R. L. Changes in blood volume in patients with edema of renal origin. J. clin. Invest. 1931, 9, 589.

20. Rapaport, E., H. Yamauchi, J. Green, E. Brown, and J. Hopper. The central circulation in nephrotics. Fed. Proc. 1960, 19, 87.

21. Baez, S., A. Mazur, and E. Shorr. Hepatorenal factors in circulatory homeostasis. XX: Antidiuretic action of hepatic vaso-depressor VDM (ferritin). Amer. J. Physiol. 1950, 162, 198.

22. Bohr, D. F., D. C. Brodie, and D. H. Cheu. Effects of electrolytes on arterial muscle contraction. Circulation 1958, 17, 746.

23. Hanenson, I. B. Effect of electrolytes and hormones on contraction of arterial smooth muscle (abstract). Circulation 1962, 26, 727.

24. Napodano, R. J., F. S. Caliva, C. Lyons, J. DeSimone, and R. H. Lyons. The reactivity to angiotensin of rabbit aorta strips after either alterations of external sodium environment or direct addition of benzydroflumethiazide. Amer. Heart J. 1962, 64, 498.

25. Friedman, S. M., and D. B. Allardyce. Sodium and tension in an artery segment. Circulat. Res. 1962 $11,84$.

26. Merril, J. P., A Guinand-Baldo, and C. Giordana. The effect of chlorothiazide on norepinephrine response in human hypertension (abstract). Clin. Res. 1958, 6, 230.

27. Freis, E. D., A. Wanko, H. W. Schnaper, and E. D. Frohlich. Mechanism of the altered blood pressure responsiveness produced by chlorothiazide. J. clin. Invest. 1960, 39, 1277.

28. Eckstein, J. W., F. M. Abboud, and S. A. Pereda. The effect of norepinephrine on cardiac output, arterial blood pressure, and heart rate in dogs treated with chlorothiazide. J. clin. Invest. 1962, 41, 1578.

29. Bock, K. D., and F. Gross. Abschwachung pressorischer Wirkungen Dusch Sali Diuretica. NaunynSchniedeberg's Arch. exp. Path. Pharmak. 1960, 238, 339.

30. Lauwers, P., and J. Conway. Effect of long-termed treatment with chlorothiazide on body fluids, serum 
electrolytes, and exchangeable sodium in hypertensive patients. J. Lab. clin. Med. 1960, 56, 401.

31. Tobian, L., J. Janecek, J. Foker, and D. Ferreira. Effects of chlorothiazide on renal juxtaglomerular cells and tissue electrolytes. Amer. J. Physiol. 1962, 202, 905.

32. Orbison, J. L. Failure of chlorothiazide to influence tissue electrolytes in hypertensive and non-hypertensive nephrectomized dogs. Proc. Soc. exp. Biol. (N. Y.) 1962, 110, 161.

33. Varnauskas, E. G. Cramér, R. Malmcroma, and L. Werkö. Effect of chlorothiazide on blood pressure and blood flow at rest and on exercise in patients with arterial hypertension. Clin. Sci. 1961, 20, 407.
34. Laragh, J. H. The mode of action and use of chlorothiazide and related compounds. Circulation 1962, 26, 121.

35. Sparks, H., and D. F. Bohr. Relative responsiveness to angiotensin of isolated smooth muscle of arteries and veins. Physiologist 1962, 5, 215.

36. Bock, K. D., and F. Gross. Renin and angiotensin tachyphylaxis. Circulat. Res. 1961, 9, 1044.

37. Langford, H. G, C. McCao, F. Sulya, and F. Alencon. Renin and angiotensin tachyphylaxis in relation to aldosterone secretion in renal hypertension. Fed. Proc. 1962, 21, 114.

38. Finnerty, F. A., Jr. Hemodynamics of angiotensin in man. Circulation 1962, 25, 255. 